\title{
Using the Priestley-Taylor expression for estimating actual evapotranspiration from satellite Landsat ETM + data
}

\author{
ABDELKRIM KHALDI, ABDELKADER KHALDI \& ABDERRAHMANE \\ HAMIMED \\ Research on Biological Systems and Geomatics Laboratory, University of Mascara, PO Box 305, Mascara 29000, \\ Algeria \\ khaldiabd@gmail.com
}

\begin{abstract}
The quantification of evapotranspiration from irrigated areas is important for agriculture water management, especially in arid and semi-arid regions where water deficiency is becoming a major constraint in economic welfare and sustainable development. Conventional methods that use point measurements to estimate evapotranspiration are representative only of local areas and cannot be extended to large areas because of landscape heterogeneity. Remote sensing-based energy balance models are presently most suited for estimating evapotranspiration at both field and regional scales. In this study, we aim to develop a methodology based on the triangle concept, allowing estimation of evapotranspiration through the classical equation of Priestley and Taylor (1972) where the proportional coefficient $\alpha$ in this equation is ranged using a linear interpolation between surface temperature and Normalized Difference Vegetation Index (NDVI) values. Preliminary results using remotely sensed data sets from Landsat ETM+ over the Habra Plains in west Algeria are in good agreement with ground measurements. The proposed approach appears to be more reliable and easily applicable for operational estimation of evapotranspiration over large areas.
\end{abstract}

Key words remote sensing; triangle concept; energy balance; evapotranspiration; vegetation index; surface temperature; Priestley-Taylor

\section{INTRODUCTION}

Monitoring the transfers of mass and energy at a surface is crucial for hydrological and vegetation resources management. It is also necessary for a better comprehension and prediction of hydrological and climatic systems. Remote sensing is an excellent tool for this monitoring as it provides information related to mass and energy transfers, and particularly to evapotranspiration fluxes (Hamimed et al. 2009).

Evapotranspiration is one of the fundamental processes controlling the equilibrium of our planet. It constitutes the link between the hydrological and energetic equilibrium at the soil-vegetationatmosphere interface and its knowledge is crucial for climatic and agrometeorological studies.

Furthermore, the estimation of actual evapotranspiration, using visible and infrared satellite remote sensing data, has been at the centre of several methodological approaches during the last years (Li et al. 2009). The deterministic models based on more complex models such as SoilVegetation-Atmosphere Transfer models (SVAT) (Boulet et al. 2007, Li et al.2009) are mainly used for estimating evapotranspiration, surface energy exchanges and water balance. Most of the transfer mechanisms (radioactive, turbulent, and water transfers) and some physiological processes (photosynthesis, stomata regulation) are described. Their time resolution is less than one hour, in agreement with the dynamic of atmospheric and surface processes. However, these models are more cumbersome and use many parameters which are difficult to measure, making them unsuitable for spatial integration in models that are very sensitive to such parameters (Jacob 1999). From an operational point of view, we prefer using semi-empirical algorithms that express the convective flux through simple relationships. In most cases, these algorithms have been developed for determining instantaneous or daily evapotranspiration. The "simplified" semi-empirical relationship has allowed expressing the daily actual evapotranspiration based on the difference between the midday surface and air temperature difference (Seguin and Itier 1983). The advantage of these relationships is to avoid three problems: (1) the estimation of the roughness length (involved in the sensible heat flux), (2) the lack of continuous measurement of surface temperature, and (3) the estimation of the soil heat flux, which is negligible on daily timescales. However, it has limitations related to poor spatial representativeness of air temperature, measured locally, and the difficulty of taking into account the surface heterogeneity. 
To take into account the fraction of vegetation cover in interpreting thermal infrared measurements, Gilles et al. (1997) proposed a so-called "Triangle" method in which they exploit the dimensions of a triangle resulting from the correlation between vegetation indices and surface temperature, highlighting the potential of this approach in estimating evapotranspiration.

Another way to estimate evapotranspiration is the so-called "residual" method, in which the latent heat flux is derived as the residual term of the energy balance equation (Kustas et al. 1994, Su 2002). The implementation of these methods often requires additional information (weather, land use, vegetation height, etc.) at the time of satellite overpass.

The volition to use only information from remote sensing led Bastiaanssen et al. (1995) to develop an algorithm called SEBAL (Surface Energy Balance Algorithm for Land) to solve the energy balance equation with a spatial approach assuming the existence of sites under extreme water conditions. The properties of these sites are used for determining some variables of the soil-plantatmosphere interface not accessible with remote sensing (wind speed, the speed of thermal stability of the atmosphere, the resistance to turbulent transfer and temperature air).

The overall intent of this study is to explore means for obtaining evapotranspiration maps for irrigated areas in Algeria, where ground data are scarce and hard to collect. A remote sensing approach is required to be routinely applied as a tool for providing both historical and near-real time evapotranspiration and surface energy fluxes for performing a better management of the agricultural water resources of the area. For this purpose, we used data from Landsat ETM+ satellite to develop a methodology based on the triangle concept for estimating evapotranspiration through the classical expression of Priestley and Taylor (1972).

\section{MATERIAL AND METHODS}

\section{The study area}

The study area corresponds to the agricultural plain of Habra, which houses the irrigation area of Mohammadia. It is located in northwestern Algeria (Oran) between longitudes $0^{\circ} 9^{\prime} \mathrm{W}$ and $0^{\circ} 6^{\prime} \mathrm{E}$ and latitude $35^{\circ} 34^{\prime} \mathrm{N}$ and $35^{\circ} 43^{\prime} \mathrm{N}$. It covers an area of $413 \mathrm{~km}^{2}$ (Fig. 1).

The selected area is part of the great interior plain of Macta, which is the receptacle of the second watershed of Algeria by its area $\left(14500 \mathrm{~km}^{2}\right)$ and only communicates with the Mediterranean Sea by a narrow channel. The average altitude is about $40 \mathrm{~m}$.

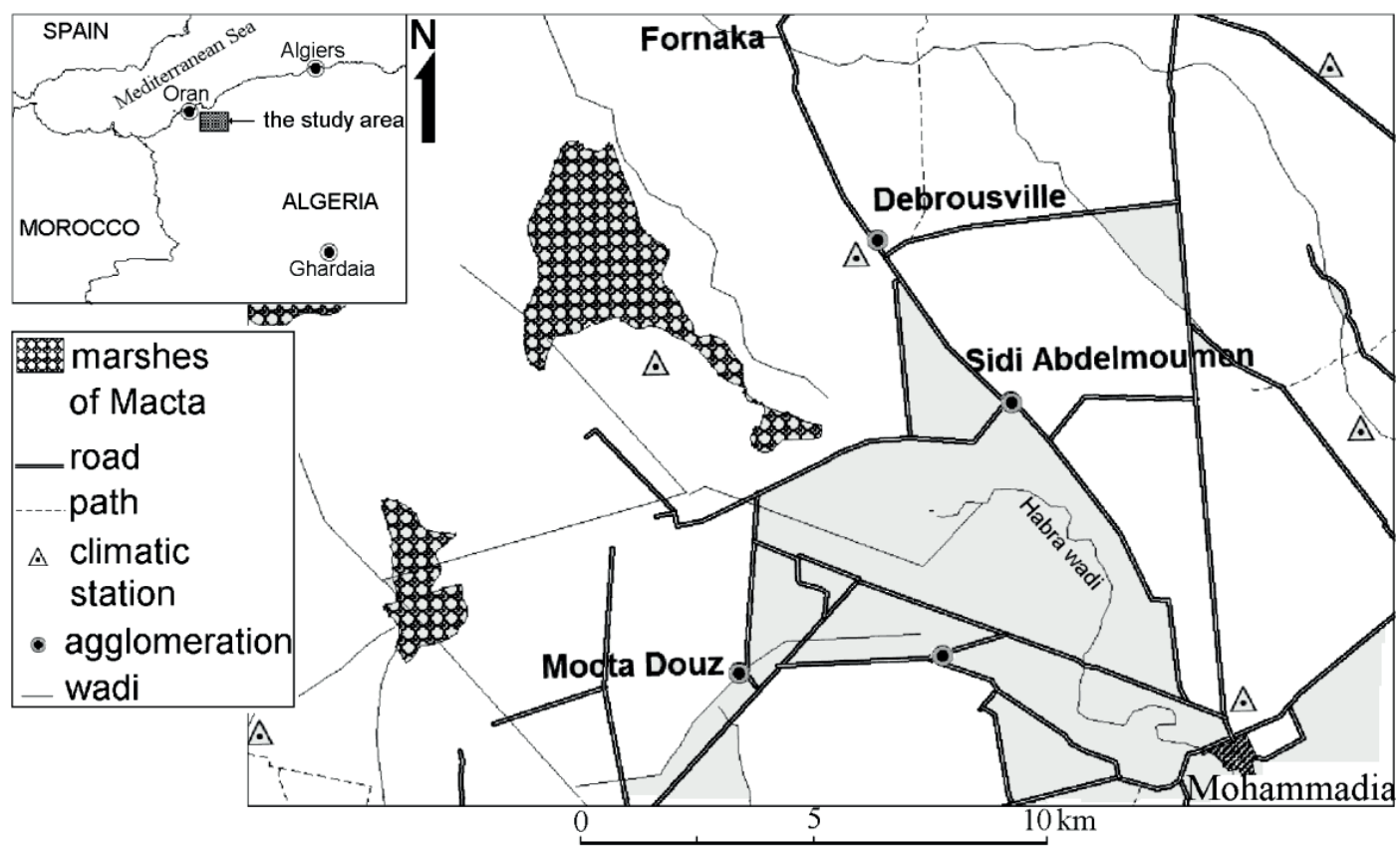

Fig. 1 Map of the study area located in the Habra plain (Algeria). 
The climate in the study region is Mediterranean semi-arid with mild winter. Two main periods characterize this region, a rainy period during the months of autumn, winter and early spring, and a dry and hot summer. The minimum air temperature during winter is $6^{\circ} \mathrm{C}$; summer is usually dry and warm and the maximum air temperature is equal to $42^{\circ} \mathrm{C}$. The average annual rainfall for the period 1980-2005 is about $450 \mathrm{~mm}$.

\section{Remote sensing and weather data}

The data set used in this study consists of seven spectral bands of Landsat-7 ETM+ (Enhanced Thematic Mapper Plus) sensor acquired on 29 May 2000 at 10:30 h GMT. Optical bands (bands 1, $2,3,4,5$ and 7) were used for albedo and vegetation index calculations. Thermal band (band 6) was used for surface temperature. Spatial resolution is $30 \times 30 \mathrm{~m}$ on the optical bands and $60 \times 60 \mathrm{~m}$ on the thermal band. This high spatial resolution is well suited for monitoring evapotranspiration on heterogonous landscapes.

Remote sensing data are supplemented by meteorological measurements for temperature and humidity of air, wind speed, global radiation, relative sunshine duration and daily evapotranspiration. These measurements are collected from six weather stations (Mohammadia, Debrousville, Sidi Abdemoumen, Sahouria, Menasria and Elghomri) located in the study area.

\section{Model description}

The latent heat flux which represents the energy consumed by evapotranspiration is estimated in pixel basis from the Priestley-Taylor expression (Priestley and Taylor, 1972), slightly modified by Flint et al. (1991):

$$
\lambda E=\alpha_{e} \frac{\Delta}{\Delta+\gamma} \cdot(R n-G)
$$

where $\alpha_{e}$ is the modified Priestley-Taylor parameter, $\gamma$ is the psychrometric constant, $\Delta$ is the slope of saturated vapour pressure, $R n$ is the net radiation and $G$ is the soil heat flux.

Equation (1) constitutes a generalization of the Priestley-Taylor expression in the case of unsaturated water areas by introducing the $\alpha_{e}$ parameter that depends on the surface moisture and it ranges from 0 to 1.26 .

The slope of saturated vapour pressure $(\Delta)$ is related to the air temperature $\left(T_{a}\right)$ as (Allen et al.1998):

$$
\Delta=\frac{2503.058}{\left(T_{a}+237.3\right)} \exp \left(\frac{17.27 T_{a}}{T_{a}+237.3}\right)
$$

For estimating $\alpha_{e}$ on a pixel basis, we suggest an expression that combines the temperature vegetation dryness index (TVDI) (Sandholt et al. 2002) and the vegetation cover fraction $\left(f_{c}\right)$ as follows:

$$
\alpha_{e}=1.26 \cdot(1-T V D I) \cdot f_{c}
$$

where $f_{c}$ is expressed by (Baret et al. 1995):

$$
f_{c}=1-\left(\frac{N D V I_{\max }-N D V I}{N D V I_{\max }-N D V I_{\text {min }}}\right)^{0,4631}
$$

and the TVDI index is defined by:

$$
T V D I=\frac{T_{o}-T_{\text {omin }}}{T_{\text {omax }}-T_{\text {omin }}}
$$

where $T_{\text {omin }}$ and $T_{\text {omax }}$ are the minimum and maximum temperatures for a given NDVI value, respectively.

The TVDI illustrates graphically the surface temperature as a function of NDVI. Its graphical space forms a triangle in which all combinations between NDVI and surface temperature are assumed 
shown (Fig. 2). The three points of the triangle, corresponding to the extreme surface conditions in terms of surface temperature and NDVI, allow deduction of the extreme values $T_{\text {omin }}, T_{\text {omax }}, N D V I_{\min }$ and $N D V I_{\max }$ for the surface temperature and NDVI, respectively (Jiang and Islam 2001).

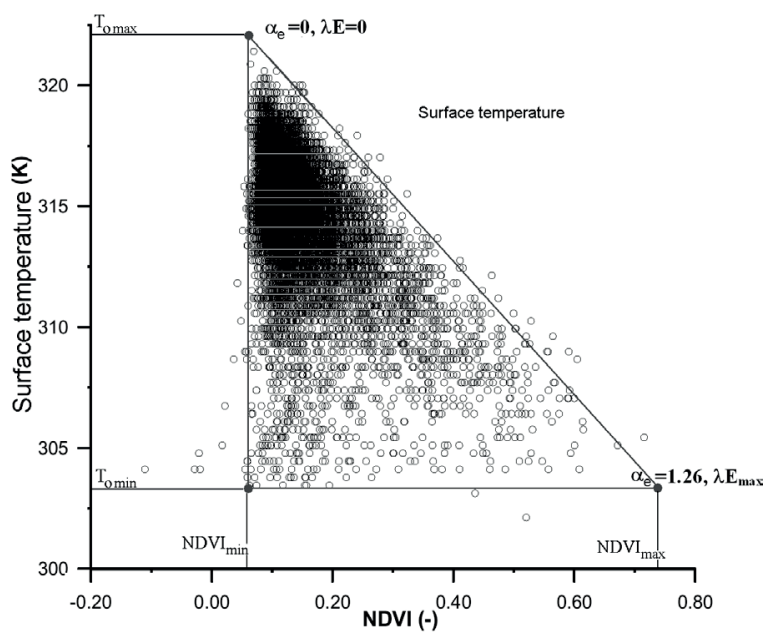

Fig. 2 Plot of surface temperature versus normalized difference vegetation index (NDVI).

The net radiation $(R n)$ is expressed as:

$$
R n=\left(1-r_{o}\right) R g+L_{\downarrow}-L_{\uparrow}
$$

where $R g$ is the incoming global radiation, partly reflected depending on the albedo $r_{o}, L \downarrow$ and $L \uparrow$ are the incoming and the outgoing long wave radiations, respectively. The incoming global radiation $(R g)$ is obtained from meteorological observations. The incoming and outgoing long wave radiation ( $L \downarrow$ and $L \uparrow)$ are estimated from the Stephan-Boltzman law using surface temperature and air temperature, respectively.

The soil heat flux $G$ is empirically estimated using the expression suggested by Bastiaanssen et al. (1995):

$$
\frac{G}{R n}=\frac{T_{o}}{r_{o}}\left[0.0032 \cdot r_{o}+0.0064 \cdot r_{o}^{2}\right]\left[1-0.98 \cdot(N D V I)^{4}\right]
$$

involving albedo, vegetation index, surface temperature and net radiation.

\section{RESULTS AND DISCUSSION}

Through modelling the latent heat flux, it has been shown that the basic parameters (albedo, vegetation index and surface temperature) obtained from the satellite imagery lead to the determination of the latent heat flux $(\lambda E)$ using the Priestley-Taylor expression.

The albedo was derived from a combination of reflectance in the short wavelengths bands. It varies for canopy on the image between 0.15 and 0.19 , which seems acceptable.

Indeed, surface temperature $\left(T_{o}\right)$ is indirectly linked to the latent heat flux $(\lambda E)$ through the energy balance equation (Seguin and Itier 1983). It provides important information on surface water status. However, the NDVI and albedo, although they provide interesting information in interpretation of thermal data (Menenti et al. 1989, Carlson 2007), are less significant in the discrimination of surface water status.

The results presented in Table 1 summarize the energy fluxes and Priestley-Taylor parameter for different land use units. It was noted that high values of latent heat flux were observed on the irrigated areas with dense vegetation and water bodies, while low values occur on the bare soils, corresponding to high values of albedo. This allows emphasizing that the spatial distribution of latent heat flux derived from the Priestley-Taylor expression is correlated to the water regimes of the different land use units. 


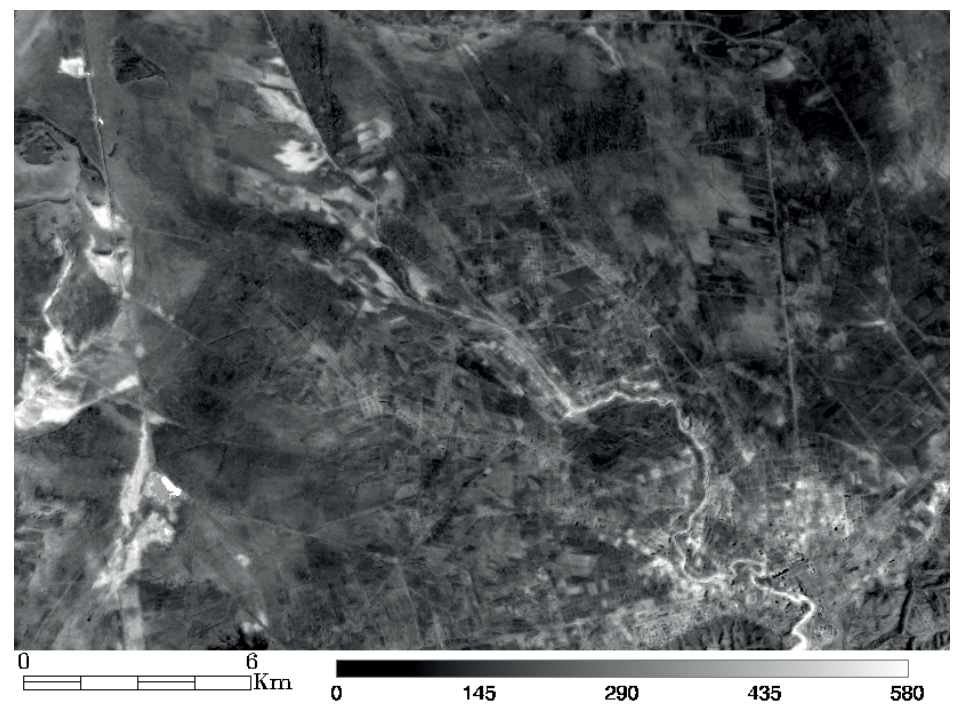

Fig. 3 Latent heat flux map in the study area.

In Fig. 3, actual evapotranspiration varies between 0 and $580 \mathrm{~W} \cdot \mathrm{m}^{-2}$ with a clear dominance of surfaces subject to water stress more or less strong having low $\lambda E$ values. However, the optimal water condition, which leads to high $\lambda E$ values, is only observed in a small area.

Another way to estimate the $\alpha_{e}$ parameter is based on the inversion of the latent heat flux derived from the SEBAL model. The comparison of the proposed approach and SEBAL model estimates of the $\alpha_{e}$ parameter showed good agreement (Fig.4(a)) which justifies the validity of the used approach.

Table 1 Variation of surface energy fluxes and the alpha parameter with land use in the study area.

\begin{tabular}{lllll}
\hline Land use units & $\begin{array}{l}R n \\
\left(\mathrm{Wm}^{-2}\right)\end{array}$ & $\begin{array}{l}G \\
\left(\mathrm{Wm}^{-2}\right)\end{array}$ & $\begin{array}{l}\alpha_{e} \\
(-)\end{array}$ & $\begin{array}{l}\lambda E \\
\left(\mathrm{Wm}^{-2}\right)\end{array}$ \\
\hline Dense vegetation & 720.1 & 155.6 & 1.12 & 329.9 \\
Moderate vegetation & 665.6 & 172.4 & 0.68 & 184.6 \\
Sparse vegetation or bare soil & 667.4 & 178.9 & 0.35 & 137.3 \\
Marshes or open water & 673.6 & 157.9 & 1.24 & 365.1 \\
\hline
\end{tabular}
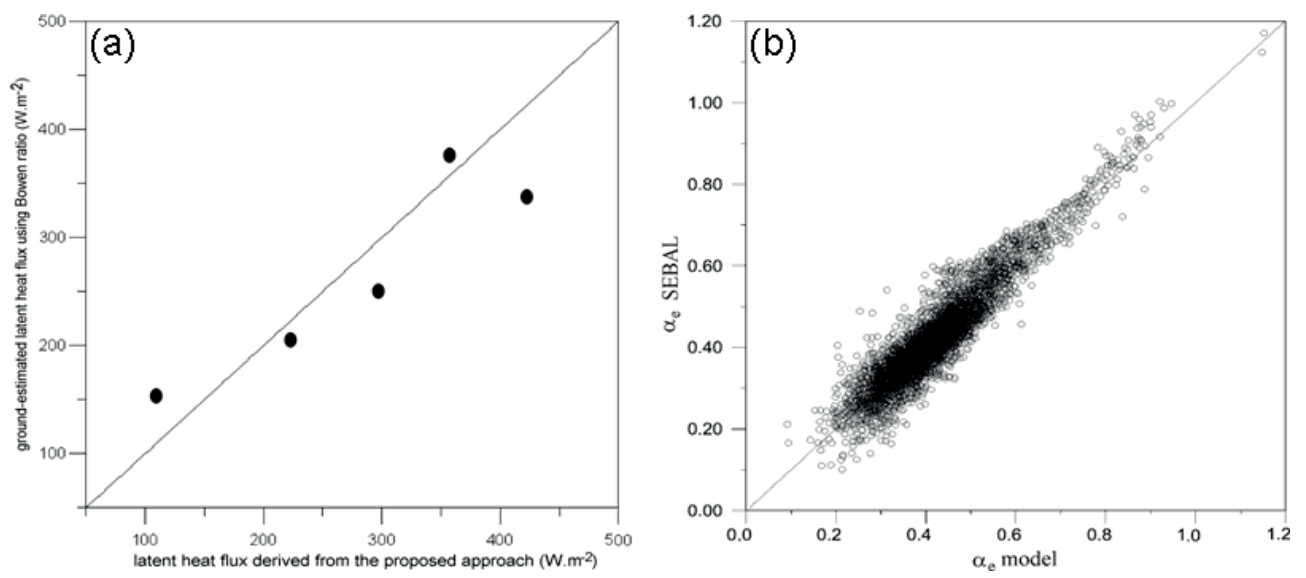

Fig. 4 Comparisons of ground-based and satellite-derived estimates of latent heat flux (a) and of the proposed approach and SEBAL model estimates of the $\alpha_{e}$ parameter (b).

Another method can be used for validating the obtained results. It is to compare latent heat flux values obtained from the proposed approach with those estimated on the ground using Bowen ratio. The result of this comparison shows (Fig. 4(b)) a significant discrepancy between remote sensing and ground estimates of latent heat flux, with a RMSE about $49.6 \mathrm{~W} \cdot \mathrm{m}^{-2}$ and a correlation coefficient 
of 0.84 , that was ascribed to inaccuracies on the intermediate variables such as surface albedo, emissivity, soil heat flux and air temperature.

\section{CONCLUSION}

Recent developments in remote sensing techniques have resulted in many new applications. One of these applications is to study the interactions between land surface and atmosphere at a regional scale. The aim of this study was to develop an approach based on the Priestley-Taylor expression for mapping evapotranspiration from Landsat-7 ETM+ data for irrigated areas in Algeria, where ground data are scarce and hard to collect.

The results obtained confirm the opportunities presented by high resolution remote sensing satellites, such as Landsat ETM+, to retrieve the evapotranspiration, assess the water stress degree and clearly differentiate the parcels subject to different water systems. However, the evapotranspiration and surface energy fluxes estimates cannot be regarded as very accurate compared to data points. We noted a significant discrepancy between remote sensing and ground estimates of latent heat flux that was ascribed to inaccuracies on the intermediate variables such as surface albedo, emissivity, soil heat flux and air temperature.

Despite these inaccuracies, the used approach is quite suitable for a real exploitation of satellite data to estimate a number of parameters at the soil-plant-atmosphere continuum. These parameters have the advantage of being spatialised and provide a spatiotemporal coverage better than the data points measured operationally. However, they pose the problem of being indirect and require the use of radiative transfer modelling within the atmosphere and at the surface for their interpretation in terms of physical parameters.

\section{REFERENCES}

Allen, R. G.. et al. (1998) Crop evapotranspiration-Guidelines for computing crop water requirements-FAO Irrigation and drainage paper 56. FAO, Rome, 300, 6541.

Baret, F.. Clevers. J. G. P. W.. and Steven. M. D. (1995) The robustness of canopv gap fraction estimates from red and nearinfrared reflectances: a comparison of approaches. Remote Sensing of Environment 54(2), 141-151.

Bastiaanssen. W. G. M. (1995) Regionalization of surface flux densities and moisture indicators in composite terrain: a remote sensing approach under clear skies in Mediterranean climates. LandbouwuniversiteitteWageningen.

Boulet, G., et al. (2007) Monitoring water stress using time series of observed to unstressed surface temperature difference. Agricultural and Forest Meteorology 146(3), 159-172.

Carlson. T. (2007) An overview of the "triangle method" for estimating surface evapotranspiration and soil moisture from satellite imagery. Sensors 7(8), 1612-1629.

Flint, A. L. and Childs, S. W. (1991) Use of the Priestley-Taylor evaporation equation for soil water limited conditions in a small forest clearcut. Agricultural and Forest Meteorology 56(3), 247-260.

Gillies, R. R., Kustas, W. P. and Humes, K. S. (1997) A verification of the "triangle" method for obtaining surface soil water content and energy fluxes from remote measurements of the Normalized Difference Vegetation Index (NDVI) and surface. International Journal of Remote Sensing 18(15), 3145-3166.

Hamimed. A.. et al. (2009) Estimation of daily actual evapotranspiration in Algerian semiarid environment with satellite ASTER. EARSeLe Proceedings 8(2), 140-151.

Jacob. F. (1999) Utilisation de la télédétection courtes longueurs d'onde et infrarouge thermique à haute résolution spatiale pour l'estimation des flux d'énergie à l'échelle de la parcelle agricole. Thèse de l'université Paul Sabatier, Toulouse, 3.

Jiang, L and Islam. S. (2001) Estimation of surface evaporation map over southern Great Plains using remote sensing data. Water Resources Research 37(2), 329-340.

Kustas. W. P.. et al. (1994) Using satellite remote sensing to extrapolate evapotranspiration estimates in time and space over a semiarid rangeland basin. Remote Sensing of Environment 49(3), 275-286.

Li, Z. L., et al. (2009) A review of current methodologies for regional evapotranspiration estimation from remotely sensed data. Sensors 9(5), 3801-3853.

Menenti. M.. et al. (1989) Linear relationships between surface reflectance and temperature and their application to map actual evaporation of groundwater. Advances in Space Research 9(1), 165-176.

Moran, M. S., et al. (1994) Estimating crop water deficit using the relation between surface-air temperature and spectral vegetation index. Remote sensing of environment 49(3), 246-263.

Priestley, C. H. B. and Tavlor, R. J. (1972) On the assessment of surface heat flux and evaporation using large-scale parameters. Monthly Weather Review 100(2), 81-92.

Sandholt. I.. Rasmussen. K. and Andersen. J. (2002) A simple interpretation of the surface temperature/vegetation index space for assessment of surface moisture status. Remote Sensing of Environment 79(2), 213-224.

Seguin, B. and Itier, B. (1983) Using midday surface temperature to estimate daily evaporation from satellite thermal IR data. International Journal of Remote Sensing 4(2), 371-383.

Su, Z. B. (2002) On estimation of turbulent heat fluxes and evaporation with radiometric measurements: past, present and future. RecentAdvances in Quantitative RemoteSensing, 319. 